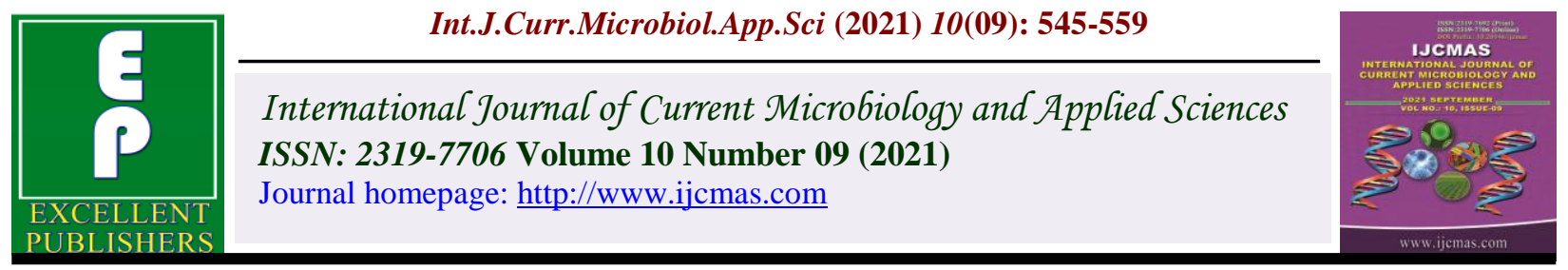

Original Research Article

https://doi.org/10.20546/ijcmas.2021.1009.063

\title{
Effect of Host Plants and Potting Mixture on Growth of Sandalwood Seedlings at Nursery Stage
}

\author{
Shubhashree Sahu*, V. Maheswarappa, Ramakrishna Hegde, \\ R. N. Kencharaddi and B. N. Sathish
}

Department of Silviculture and Agroforestry, College of Forestry, Ponnampet, Keladi Shivappa Nayaka University of Agricultural and Horticultural Sciences, Shivamogga, India

*Corresponding author

\section{A B S T R A C T}

Keywords

Sandalwood, Potting mixture, survival, host plants, growth, performance

Article Info

Accepted:

20 August 2021

Available Online:

10 September 2021
Sandalwood (Santalum album L.) is one of the most valuable commercially cultivated aromatic species throughout the world. However, the availability of quality planting stock isthe current bottleneck in its establishment on large scale. The major problems, noticed during quality planting stock production in nurseries are scarce knowledge about host-parasite relationship and use of appropriate potting mixture apart from its seed germination. In this regard two experiments were carried out at the College of Forestry, Ponnampet during 2020-2021 to identify suitable host plant and potting mixture. Growth parameters were recorded after 90, 180 and 270 days of transplanting sandal seedlings into treatments. After 270 days of transplanting, the host plant A. lebbeck recorded higher survival of sandal seedlings $(81.89 \%)$ and the host plant $C$. junghuhniana had higher height growth $(10.40 \mathrm{~cm})$ with collar diameter $2.33 \mathrm{~mm}$. Potting mixture sand, soil, vermicompost, G. intraradices with $C$. Junghuhninana found effective for height $(18.25 \mathrm{~cm})$ and collar diameter $(2.58 \mathrm{~mm})$.

\section{Introduction}

Sandalwood (Santalum album L.) is a small evergreen hemi root parasitic tree of the family 'Santalaceae' renowned for its aromatic oil and fragrant heartwood. The generic nameis derived from the Greek term 'santalon' meaning 'sandalwood' and species name from Latin 'albus' meaning 'white', in allusion to the bark. Santalum album is a small evergreen tree, a partial root parasite, attaining a height of 12 to 13 meters and girth of 1 to 2.4 meters with slender drooping as well as erect branching (Srinivasan et al., 1992). Globally, sandal family is distributed between $30^{\circ} \mathrm{N}$ and $40^{\circ} \mathrm{S}$ from Indonesia in the West 
toJuan Fernandez Island in the north to New Zealand in the South. In India, its distribution is limited to an area of about $9600 \mathrm{~km}^{2}$, mostly in the deciduous forests of Deccan Peninsular India (Gairola et al., 2008).The South Indian states, Karnataka and Tamil Nadu together account more than 90 per cent of the natural population of $S$. album (Dutt and Verma, 2005).

The annual production of sandalwood in India has declined from 4000 tonnes in 1965-1975 to nearly 2000 tonnes during 1999-2000 (Vishwanath et al., 2009). India exports around 2000tonnes of wood and 100 tonnes of oil annually to various countries, which accounts 99 percent of sandalwood tree oil produced in the world (Lakshmisita and Bhattacharya, 1998).India suffered a substantial decline in sandalwood production from 3176 tons per year during 1960-65 to 1500 tons per year in 1997-98, and to 500 tons per year in 2007 (Jain et al., 2003, Gairola et al., 2007).and 100 tons per year in 2014-2015. Also, oil production declined from 60 tons per year during 1981-1994 to 40-50 tons per year during 1999-2000 (Ananthapadmanabha, 2000).

Over exploitation, illicit felling, rampant smuggling and illegal trade of sandalwood have resulted in decline of population and genetic erosion (Annapurna et al., 2007). Although demand for sandalwood and oil is increasing, supplies are declining and it is necessary to bring larger area under commercial cultivation (Rai and Sharma, 1990). In order to meet the growing demand and sustainable utilization of sandalwood, a large scale quality planting stock is required for planting under social forestry and massive afforestation programmes. Simultaneously, nursery techniques in raising quality seedlings need to be standardized for production of quality planting stocks which is a pre-requisite for the successful plantation in the field.
The regeneration and establishment of sandal tree have been problematic because of poor understanding of host-parasite relationships (Surendran et al., 1998). To ensure the success of $S$. album plantations, quality seedlings are needed. The culture medium plays an important role during the entire cultivation process which provides water, air, mineral nutrients and physical support to the seedlings (Xiaojin et al., 2009). In this context, for the good quality production of sandalwood seedlings at nursery stage, host plants and potting mixture with mycorrhizal inoculums was considered in assessing the affects its on survival and growth of sandalwood seedlings.

\section{Materials and Methods}

The experiment was conducted at College of Forestry, Ponnampet, Kodagu during 20202021. To study the effect of host plant and potting mixture which contains AM fungi on growth and development of quality seedlings of $S$. album, the following treatment were imposed. In main plot treatment, three host plants Albizia lebbeck (H1), Casuarina junghunhiana $(\mathrm{H} 2)$ and Alternanthera sessilis (H3) were imposed. In sub-plot treatment, nine treatment combinations i.e. sand, soil and FYM (T1), sand, soil, FYM and Glomus fasiculatum (T2), sand, soil, FYM and Glomus intraradices (T3), burnt rice husk, soil and FYM (T4), burnt rice husk, soil, FYM and Glomus fasiculatum (T5), burnt rice husk, soil, FYM and Glomus intraradices(T6), sand, soil and vermicompost (T7), sand, soil, vermicompost and Glomus fasiculatum (T8) and sand, soil, vermicompost and Glomus intraradices (T9) were imposed.

The experiment was laid out in Split plot design. Host plants were considered as main plot, and potting mixtures along with AM fungi as sub-sub plot treatment. There were three main plots and nine sub plots. All the treatments were replicated thrice with 30 
plants per replication and thus comprised of 90 plants per treatment.

The polybags filled with potting mixture were arranged according to treatments and replications. The medium containing AM fungi strains were added at the rate of $15 \mathrm{~g}$ per polythene bag to the filled polythene bags according to the treatments. The polythene bags were maintained under shade net condition. The sandal seedlings at four leaf stage were transplanted to the polythene bags. The host species were then planted into the polythene bags according to main plot and sub plot treatment combinations i.e. nine sub treatments under each of the three main plot treatments.

\section{Observations}

Observations on seedlings survival and plant parameters such as plant height, collar diameter were recorded at three months interval i.e. after 90, 180 and 270 days of transplanting respectively. The relative growth rate for the above parameters was worked out after 270 days of transplanting.

\section{Results and Discussion}

\section{Seedling survival}

The effect of host plant on survival rate of the seedlings was conspicuous at 90 days of transplanting. The survival rate was higher with A.sessilis H3 (97.89 \%) followed by A.lebbeck H1 (97.00\%). After 180 days of transplanting the similar trend was observed where seedlings with A.sessilis had higher survival rate $(89.07 \%)$. However, after 270 days of transplanting seedlings with A.lebbeck had higher survival rate $(81.89 \%)$ followed by A.sessilis (81.07\%) (Table 1).

Among the host plant, higher survival rate of seedlings was observed in pot host H3
(A.sessilis) (97.89 \%) due to herbaceous growth and lateral spread of roots at the initial stage of sandal growth helped in early uptake of nutrients from potting mixture after 90 and 180 days of transplanting. These results are in confirmation with the reports of Radomiljac (1994) who found pot host species A.sessilis to be best as hosts to $S$. album.

After 270 days of transplanting, higher survival of sandal seedlings were noticed in host plant A.lebbeck (81.89\%) and A.sessilis $(81.07 \%)$. The mortality rate was higher in host plant C.junghuhniana (10.60\%) than A.lebbeck (7.99\%) (Fig 1). The final survival of seedlings in A.lebbeck could be attributed to interaction of roots of leguminous plants and uptake of moisture and supply of nutrients. These results are in line with findings of Annapurna et al., (2007) who suggested that leguminous plants are essential at the nursery stage for better growth and survival and obtained 80 percent survival even after 180 days of transplanting.

After 90 days of transplanting, there was 100 percent survival of the seedlings in the potting mixture combinations of burnt rice husk, soil, FYM and G.intraradices (T6), sand, soil, vermicompost and G.fasiculatum (T8) and sand, soil, vermicompost and G.intraradices (T9). After 180 days of transplanting, treatment of burnt rice husk, soil, FYM and G.fasiculatum (T5) recorded higher survival $(92.22 \%)$. The survival was cent per cent in potting mixture containing sand, soil, vermicompost with G.intraradices after 90 days of transferring four leaves stage of sandal seedlings to polythene bags. The potting mixture containing vermicompost did not support the survival of the seedlings up to 270 days of transplanting could be due to more moisture accumulation resulted in death of seedlings. However, after 270 days of transplanting, potting mixture with burnt rice husk, soil and farmyard manure with 
G.fasciculatum retained the seedlings upto 84.11 per cent could be due to activity of G.fasciculatum helped in seedlings survival (Fig 2).

The interaction of $\mathrm{H} 1 * \mathrm{~T} 3, \mathrm{H} 1 * \mathrm{~T} 6, \mathrm{H} 1 * \mathrm{~T} 8$, H1*T9, H2*T5, H2*T6, H2*T8,H2*T9, $\mathrm{H} 3{ }^{*} \mathrm{~T} 2, \mathrm{H} 3 * \mathrm{~T} 5, \mathrm{H} 3 * \mathrm{~T} 6, \mathrm{H} 3 * \mathrm{~T} 8$ and $\mathrm{H} 3 * \mathrm{~T} 9$ has resulted in 100 percent survival of seedling after 90 days of transplanting. After 180 days of transplanting, the interaction effect of $\mathrm{H} 1 * \mathrm{~T} 5$ recorded higher survival percentage $(93.67 \%)$ ).After 270 days of transplanting, interaction effect of $\mathrm{H} 3 * \mathrm{~T} 8$ had higher survival of the seedlings $(87.67 \%)$.The interaction effect of A.sessilis and potting mixture sand, soil, vermicompost with G.fasciculatum had profound effect on seedling survival (87.67\%) (Fig 3). These results are in confirmation with Annapurna et al., (2007), Surata (1992) and Radomiljac(1998) where in leguminous herb resulted in more haustorial connection which draws the nutrients from potting mixture. On the contrary, sand, soil or organic matter caused poor seedling growth (Annapurna, 2002) which noticed in potting mixture sand, soil and farmyard manure. Hence, early inoculation of seedlings with arbuscular mycorrhiza fungi under nursery conditions benefited in superior and stronger growth of the seedlings as indicated by Caravaca et al.,(2003).

\section{Seedling height}

The host plant $A$. sessilis (H3) effected higher height growth of sandal seedlings $(8.51 \mathrm{~cm})$ followed by A. lebbeck $(\mathrm{H} 1)$ which was 7.18 $\mathrm{cm}$. However, after 180 days of transplanting, $\mathrm{H} 1 \mathrm{had}$ higher height $(9.17 \mathrm{~cm})$ followed by C. Junghuhniana (H2) i.e. $9.12 \mathrm{~cm}$ and after 270 days of transplanting, treatment with $\mathrm{H} 2$ had higher height growth $(10.40 \mathrm{~cm})$ followed by $\mathrm{H} 3(9.83 \mathrm{~cm})$.Seedling height in subplot treatment revealed that, treatment with sand, soil, vermicompost and G.intraradices (T9) had higher height $(8.68 \mathrm{~cm})$ (Table 2$)$.

The pot host $C$.junghuhiana had significantly influenced height growth of sandal $(10.40 \mathrm{~cm})$ followed by A.sessilis $(9.83 \mathrm{~cm})$ (Fig 4). This may be due to non-leguminous and leguminous plant at the nursery stage increased the nutrient uptake by haustoria connection with host and sandal. The growth of host plants were restricted by regular pruning so that it should not compete for resources. The potting mixture consisting of sand, soil, vermicompost with G.intraradices had profound influence on height of sandal seedlings $(13.51 \mathrm{~cm})$. At the interaction of pot host $C$. junghuhiana and potting mixture sand, soil, vermicompost with G.intraradices effected height growth of seedlings (18.01 $\mathrm{cm})$. The relative growth rate (1.69) for height was higher in $C$. junghuhiana and potting mixture sand, soil, vermicompost with G.intraradices. These results can be attributed to the fact that, structurally hosts provide protection from sun and wind as well acts as a possible source of nutrients and amino acids. Nutrients such as calcium and iron, nitrogen and phosphate (Iyengar, 1960) potassium, phosphate and magnesium (Rangaswamyet al., 1986) are supplied to sandal at nursery stage.

\section{Collar diameter}

In the main plot treatment i.e. host had nonsignificant effect on collar diameter after 90 days of transplanting. However, $\mathrm{H} 2$ (C.junghuhniana) had effected higher collar diameter $(1.39 \mathrm{~mm})$ followed by $\mathrm{H} 3$ (A.sessilis) $1.37 \mathrm{~mm}$. 
Table.1 Effect of host and potting mixture on seedlings survival at 90 days interval after transplanting

\begin{tabular}{|c|c|c|c|c|}
\hline Plot & \multirow[t]{2}{*}{ Treatment } & \multicolumn{3}{|c|}{ Seedling Survival (\%) } \\
\hline \multirow[t]{6}{*}{ Main Plot } & & 90 DAP & 180 DAP & 270 DAP \\
\hline & H1 & $9.90 *(97.00)$ & $9.48 *(89.00)$ & $9.10 *(81.89)$ \\
\hline & H2 & $9.88(96.70)$ & $9.24(84.52)$ & $8.74(75.56)$ \\
\hline & H3 & $9.94(97.89)$ & $9.49(89.07)$ & $9.05(81.07)$ \\
\hline & SEm \pm & 0.02 & 0.05 & 0.03 \\
\hline & CD@5\% & 0.09 & 0.19 & 0.11 \\
\hline \multirow[t]{11}{*}{ Sub plot } & T1 & $9.67(92.44)$ & $9.11(82.00)$ & $8.64(73.89)$ \\
\hline & $\mathbf{T} 2$ & $9.98(98.55)$ & $9.50(89.22)$ & $9.16(83.00)$ \\
\hline & T3 & $9.98(98.55)$ & $9.60(91.11)$ & $9.11(82.00)$ \\
\hline & $\mathbf{T 4}$ & $9.63(91.67)$ & $9.00(80.11)$ & $8.44(70.33)$ \\
\hline & T5 & $10.03(99.55)$ & $9.65(92.22)$ & $9.07(81.22)$ \\
\hline & T6 & $10.05(100.00)$ & $9.53(89.89)$ & $9.13(82.56)$ \\
\hline & T7 & $9.75(94.00)$ & $9.25(84.78)$ & $8.89(78.22)$ \\
\hline & T8 & $10.05(100.00)$ & $9.42(87.78)$ & $9.00(80.22)$ \\
\hline & T9 & $10.05(100.00)$ & $9.57(90.67)$ & $9.22(84.11)$ \\
\hline & SEm \pm & 0.03 & 0.06 & 0.09 \\
\hline & CD@5\% & 0.08 & 0.17 & 0.24 \\
\hline \multirow{30}{*}{$\begin{array}{c}\text { Interaction Effect } \\
\text { (Main plot X Sub plot) }\end{array}$} & H1*T1 & $9.66(92.33)$ & $9.38(87.00)$ & $9.0(80.00)$ \\
\hline & H1 *T2 & $9.97(98.33)$ & $9.45(88.33)$ & $9.22(84.00)$ \\
\hline & H1*T3 & $10.05(100.00)$ & $9.66(92.33)$ & $9.27(85.00)$ \\
\hline & H1*T4 & $9.57(90.67)$ & 9.09 (81.67) & $8.68(74.33)$ \\
\hline & H1*T5 & $9.98(98.66)$ & 9.73 (93.67) & $9.13(82.33)$ \\
\hline & H1*T6 & $10.05(100.00)$ & $9.66(92.33)$ & $9.31(85.67)$ \\
\hline & H1*T7 & $9.69(93.00)$ & $9.49(89.00)$ & $9.22(84.00)$ \\
\hline & H1*T8 & $10.05(100.00)$ & $9.54(90.00)$ & 9.09 (81.67) \\
\hline & H1*T9 & $10.05(100.00)$ & $9.36(86.67)$ & $9.00(80.00)$ \\
\hline & $\mathrm{H} 2 * \mathrm{~T} 1$ & $9.63(91.67)$ & $8.94(79.00)$ & $8.52(71.67)$ \\
\hline & H2*T2 & $9.91(97.33)$ & $9.36(86.67)$ & $9.01(80.33)$ \\
\hline & H2*T3 & $9.91(97.33)$ & 9.57 (90.67) & $9.00(80.00)$ \\
\hline & H2*T4 & $9.59(91.00)$ & 8.98 (79.67) & $8.22(66.67)$ \\
\hline & H2*T5 & $10.05(100.00)$ & $9.66(92.33)$ & $9.05(81.00)$ \\
\hline & H2*T6 & $10.05(100.00)$ & $9.27(85.00)$ & 8.75 (75.67) \\
\hline & H2*T7 & $9.69(93.00)$ & $8.65(74.00)$ & $8.32(68.33)$ \\
\hline & H2*T8 & $10.05(100.00)$ & $9.00(80.00)$ & $8.50(71.33)$ \\
\hline & H2*T9 & $10.05(100.00)$ & $9.71(93.33)$ & $9.27(85.00)$ \\
\hline & H3*T1 & $9.71(93.33)$ & $9.00(80.00)$ & $8.41(70.00)$ \\
\hline & H3*T2 & $10.05(100.00)$ & 9.68 (92.67) & $9.25(84.67)$ \\
\hline & H3*T3 & $9.97(98.33)$ & $9.56(90.33)$ & $9.05(81.00)$ \\
\hline & H3*T4 & $9.71(93.33)$ & $8.94(79.00)$ & $8.42(70.00)$ \\
\hline & H3*T5 & $10.05(100.00)$ & 9.57 (90.67) & $9.02(80.33)$ \\
\hline & H3*T6 & $10.05(100.00)$ & $9.66(92.33)$ & $9.34(86.33)$ \\
\hline & H3*T7 & $9.85(96.00)$ & $9.61(91.33)$ & $9.13(82.33)$ \\
\hline & H3*T8 & $10.05(100.00)$ & $9.71(93.33)$ & $9.41(87.67)$ \\
\hline & H3*T9 & $10.05(100.00)$ & $9.64(92.00)$ & $9.4(87.33)$ \\
\hline & SEm \pm & 0.05 & 0.10 & 0.15 \\
\hline & CD@5 \% & NS & 0.30 & 0.42 \\
\hline & CD@5\% & NS & 0.34 & 0.41 \\
\hline
\end{tabular}

$\neq$ between two sub-plot treatment means @ same level of main plot treatment

$\neq \neq$ between two main plot treatments means @ same or different levels of subplot treatment means. * Square root transformed values and figures in parenthesis are original values. 
Table.2 Effect of host and potting mixture on height of Santalum album at 90 days interval after transplanting

\begin{tabular}{|c|c|c|c|c|}
\hline Plot & \multirow[t]{2}{*}{ Treatment } & \multicolumn{3}{|c|}{ Height (cm) } \\
\hline \multirow{6}{*}{ Main Plot } & & 90 DAP & 180 DAP & 270 DAP \\
\hline & H1 & 7.18 & 7.47 & 8.25 \\
\hline & H2 & 6.43 & 9.12 & 10.40 \\
\hline & H3 & 8.51 & 9.17 & 9.83 \\
\hline & SEm \pm & 0.39 & 0.30 & 0.36 \\
\hline & CD @5\% & 1.54 & 1.17 & 1.42 \\
\hline \multirow[t]{11}{*}{ Sub plot } & T1 & 7.13 & 7.35 & 7.89 \\
\hline & T2 & 6.24 & 6.66 & 7.79 \\
\hline & T3 & 6.68 & 7.52 & 8.13 \\
\hline & T4 & 7.12 & 7.48 & 8.31 \\
\hline & T5 & 7.06 & 7.45 & 8.19 \\
\hline & T6 & 7.04 & 7.42 & 8.22 \\
\hline & T7 & 8.00 & 9.91 & 11.01 \\
\hline & T8 & 8.44 & 11.41 & 12.39 \\
\hline & T9 & 8.68 & 12.06 & 13.51 \\
\hline & SEm \pm & 0.36 & 0.42 & 0.38 \\
\hline & CD@5\% & 1.02 & 1.20 & 1.07 \\
\hline \multirow{30}{*}{$\begin{array}{c}\text { Interaction Effect } \\
\text { (Main plot X Sub plot) }\end{array}$} & H1*T1 & 7.17 & 7.35 & 8.28 \\
\hline & H1*T2 & 7.15 & 7.32 & 8.25 \\
\hline & H1*T3 & 6.76 & 7.01 & 7.58 \\
\hline & H1*T4 & 7.50 & 7.82 & 8.84 \\
\hline & H1*T5 & 7.82 & 8.16 & 8.73 \\
\hline & H1*T6 & 7.13 & 7.28 & 8.39 \\
\hline & H1 *T7 & 7.34 & 7.83 & 8.31 \\
\hline & H1*T8 & 6.87 & 7.18 & 7.66 \\
\hline & H1*T9 & 6.92 & 7.28 & 8.18 \\
\hline & H2 2 T1 & 6.58 & 6.79 & 7.19 \\
\hline & H2 2 T2 & 4.84 & 5.51 & 7.45 \\
\hline & H2 2 T3 & 6.41 & 7.50 & 8.24 \\
\hline & H2*T4 & 7.29 & 7.69 & 8.35 \\
\hline & H2*T5 & 6.76 & 7.08 & 7.85 \\
\hline & H2*T6 & 6.57 & 7.23 & 7.97 \\
\hline & H2 2 T7 & 6.58 & 11.17 & 13.17 \\
\hline & H2 2 T8 & 6.20 & 13.33 & 15.37 \\
\hline & H2*T9 & 6.70 & 15.75 & 18.01 \\
\hline & H3*T1 & 7.64 & 7.90 & 8.20 \\
\hline & H3*T2 & 6.73 & 7.14 & 7.68 \\
\hline & H3*T3 & 6.87 & 8.04 & 8.56 \\
\hline & H3*T4 & 6.56 & 6.94 & 7.74 \\
\hline & H3*T5 & 6.62 & 7.10 & 7.97 \\
\hline & H3*T6 & 7.42 & 7.77 & 8.29 \\
\hline & H3*T7 & 10.08 & 10.73 & 11.54 \\
\hline & H3*T8 & 12.24 & 13.73 & 14.15 \\
\hline & H3*T9 & 12.43 & 13.15 & 14.36 \\
\hline & SEm \pm & 0.62 & 0.73 & 0.65 \\
\hline & CD@5\% $\%^{\neq}$ & 1.77 & 2.08 & 1.85 \\
\hline & CD@5\% & 2.24 & 2.27 & 2.22 \\
\hline
\end{tabular}

$\neq$ between two sub-plot treatment means @ same level of main plot treatment

$\neq \neq$ between two main plot treatments means @ same or different levels of subplot treatment means. 
Table.3 Effect of host and potting mixture on collar diameter of Santalum album Seedlings at 90 days interval after transplanting

\begin{tabular}{|c|c|c|c|c|}
\hline Plot & \multirow[t]{2}{*}{ Treatment } & \multicolumn{3}{|c|}{ Collar diameter (mm) } \\
\hline \multirow{6}{*}{ Main Plot } & & 90 DAP & 180 DAP & 270 DAP \\
\hline & H1 & 1.36 & 1.42 & 1.63 \\
\hline & H2 & 1.39 & 1.95 & 2.20 \\
\hline & H3 & 1.37 & 2.04 & 2.23 \\
\hline & SEm \pm & 0.21 & 0.14 & 0.14 \\
\hline & CD @5\% & NS & 0.55 & 0.54 \\
\hline \multirow[t]{11}{*}{ Sub plot } & T1 & 1.45 & 1.52 & 1.66 \\
\hline & T2 & 1.41 & 1.47 & 1.62 \\
\hline & T3 & 1.24 & 1.33 & 1.52 \\
\hline & T4 & 1.42 & 1.53 & 1.76 \\
\hline & T5 & 1.34 & 1.41 & 1.69 \\
\hline & T6 & 1.44 & 1.52 & 1.70 \\
\hline & T7 & 1.50 & 2.41 & 2.79 \\
\hline & T8 & 1.36 & 2.44 & 2.62 \\
\hline & T9 & 1.21 & 2.58 & 2.84 \\
\hline & SEm \pm & 0.14 & 0.16 & 0.14 \\
\hline & CD@5\% & NS & 0.45 & 0.39 \\
\hline \multirow{30}{*}{$\begin{array}{c}\text { Interaction Effect } \\
\text { (Main plot X Sub plot) }\end{array}$} & H1*T1 & 1.48 & 1.54 & 1.64 \\
\hline & H1*T2 & 1.32 & 1.40 & 1.54 \\
\hline & H1*T3 & 1.16 & 1.18 & 1.50 \\
\hline & H1*T4 & 1.57 & 1.63 & 2.03 \\
\hline & H1*T5 & 1.38 & 1.43 & 1.62 \\
\hline & H1*T6 & 1.38 & 1.42 & 1.65 \\
\hline & H1*T7 & 1.48 & 1.50 & 1.68 \\
\hline & H1*T8 & 1.27 & 1.38 & 1.55 \\
\hline & H1*T9 & 1.23 & 1.31 & 1.46 \\
\hline & H2*T1 & 1.29 & 1.35 & 1.45 \\
\hline & H2*T2 & 1.00 & 1.08 & 1.21 \\
\hline & H2*T3 & 1.39 & 1.47 & 1.56 \\
\hline & H2*T4 & 1.45 & 1.60 & 1.72 \\
\hline & H2*T5 & 1.40 & 1.43 & 2.00 \\
\hline & H2*T6 & 1.67 & 1.75 & 1.94 \\
\hline & H2*T7 & 1.49 & 2.77 & 3.03 \\
\hline & H2*T8 & 1.34 & 2.91 & 3.17 \\
\hline & H2*T9 & 1.45 & 3.17 & 3.73 \\
\hline & H3*T1 & 1.59 & 1.68 & 1.89 \\
\hline & H3*T2 & 1.90 & 1.94 & 2.12 \\
\hline & H3*T3 & 1.17 & 1.35 & 1.50 \\
\hline & H3*T4 & 1.23 & 1.35 & 1.52 \\
\hline & H3*T5 & 1.24 & 1.36 & 1.44 \\
\hline & H3*T6 & 1.26 & 1.40 & 1.51 \\
\hline & H3*T7 & 1.53 & 2.95 & 3.65 \\
\hline & H3*T8 & 1.46 & 3.04 & 3.15 \\
\hline & H3*T9 & 0.97 & 3.26 & 3.33 \\
\hline & SEm \pm & NS & 0.39 & 0.33 \\
\hline & CD@5\% $\%^{\neq}$ & 0.43 & 0.42 & 0.37 \\
\hline & CD@5\% & 1.03 & 0.91 & 0.82 \\
\hline
\end{tabular}

$\neq$ between two sub-plot treatment means @ same level of main plot treatment $\neq \neq$ between two main plot treatments means @ same or different levels of subplot treatment means. 
Table.4 Effect of host and potting mixture on relative growth rate of Santalum album seedlings after 270 days of transplanting

\begin{tabular}{|c|c|c|c|}
\hline Main plot Treatment (Host) & $\begin{array}{l}\text { Sub plot Treatment } \\
\text { (Potting mixture) }\end{array}$ & RGRH & RGRCD \\
\hline \multirow[t]{9}{*}{ Albizia lebbeck } & $\mathrm{T} 1$ & 0.15 & 0.64 \\
\hline & $\mathbf{T} 2$ & 0.15 & 0.82 \\
\hline & T3 & 0.12 & 0.65 \\
\hline & T4 & 0.18 & 0.56 \\
\hline & T5 & 0.12 & 0.84 \\
\hline & T6 & 0.18 & 0.76 \\
\hline & T7 & 0.13 & 0.72 \\
\hline & T8 & 0.11 & 0.80 \\
\hline & T9 & 0.18 & 0.64 \\
\hline \multirow[t]{9}{*}{ Casuarina junghuhniana } & T1 & 0.09 & 0.70 \\
\hline & $\mathbf{T} 2$ & 0.54 & 1.29 \\
\hline & T3 & 0.29 & 0.86 \\
\hline & T4 & 0.15 & 0.88 \\
\hline & T5 & 0.16 & 0.85 \\
\hline & T6 & 0.21 & 0.64 \\
\hline & T7 & 1.00 & 2.23 \\
\hline & T8 & 1.48 & 2.10 \\
\hline & T9 & 1.69 & 2.84 \\
\hline \multirow[t]{9}{*}{ Alternanthera sessilis } & T1 & 0.07 & 0.83 \\
\hline & $\mathbf{T} 2$ & 0.14 & 0.54 \\
\hline & T3 & 0.24 & 1.52 \\
\hline & T4 & 0.18 & 0.96 \\
\hline & T5 & 0.21 & 0.98 \\
\hline & T6 & 0.12 & 0.89 \\
\hline & T7 & 0.14 & 3.93 \\
\hline & T8 & 0.16 & 3.42 \\
\hline & T9 & 0.15 & 5.49 \\
\hline
\end{tabular}


Fig.1 Effect of host plants on mortality of sandal seedlings at an interval of 90 days

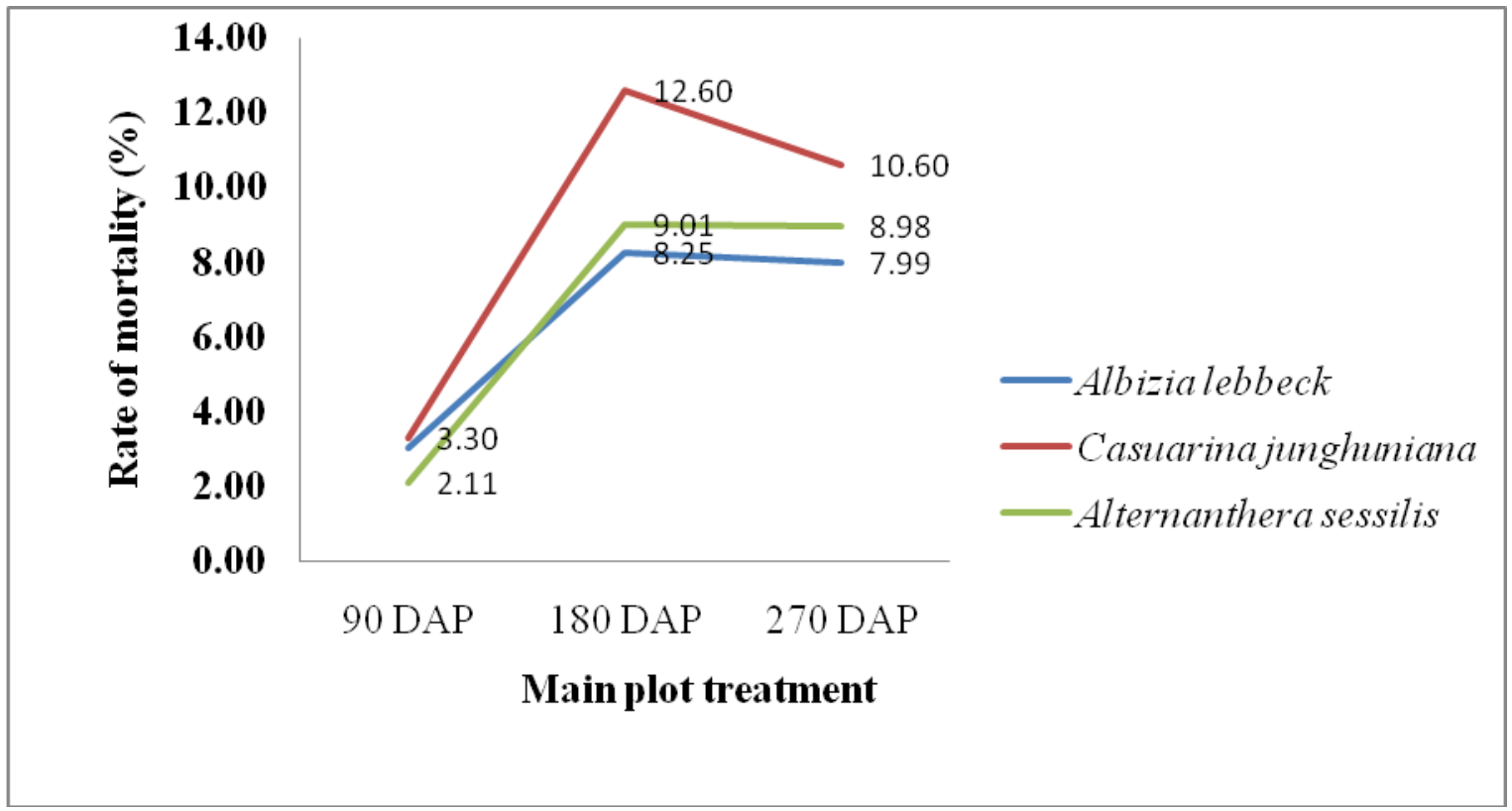

Fig.2 Effect of treatment (potting mixture) on sandal seedling mortality at an interval of 90 days

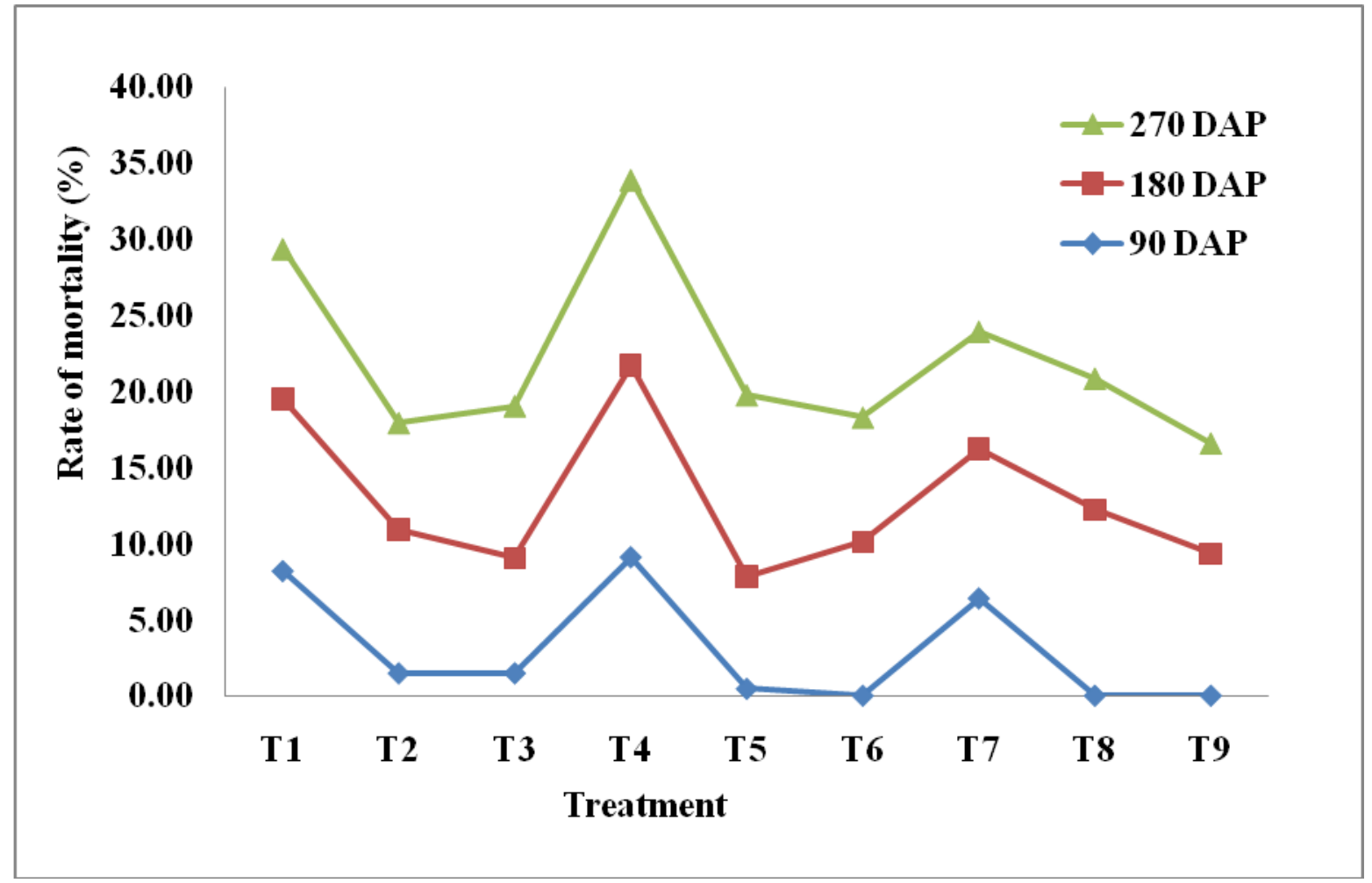


Fig.3 Interaction effect of host plant and treatment (potting mixture) on sandal seedlings Mortality at an interval of 90 days

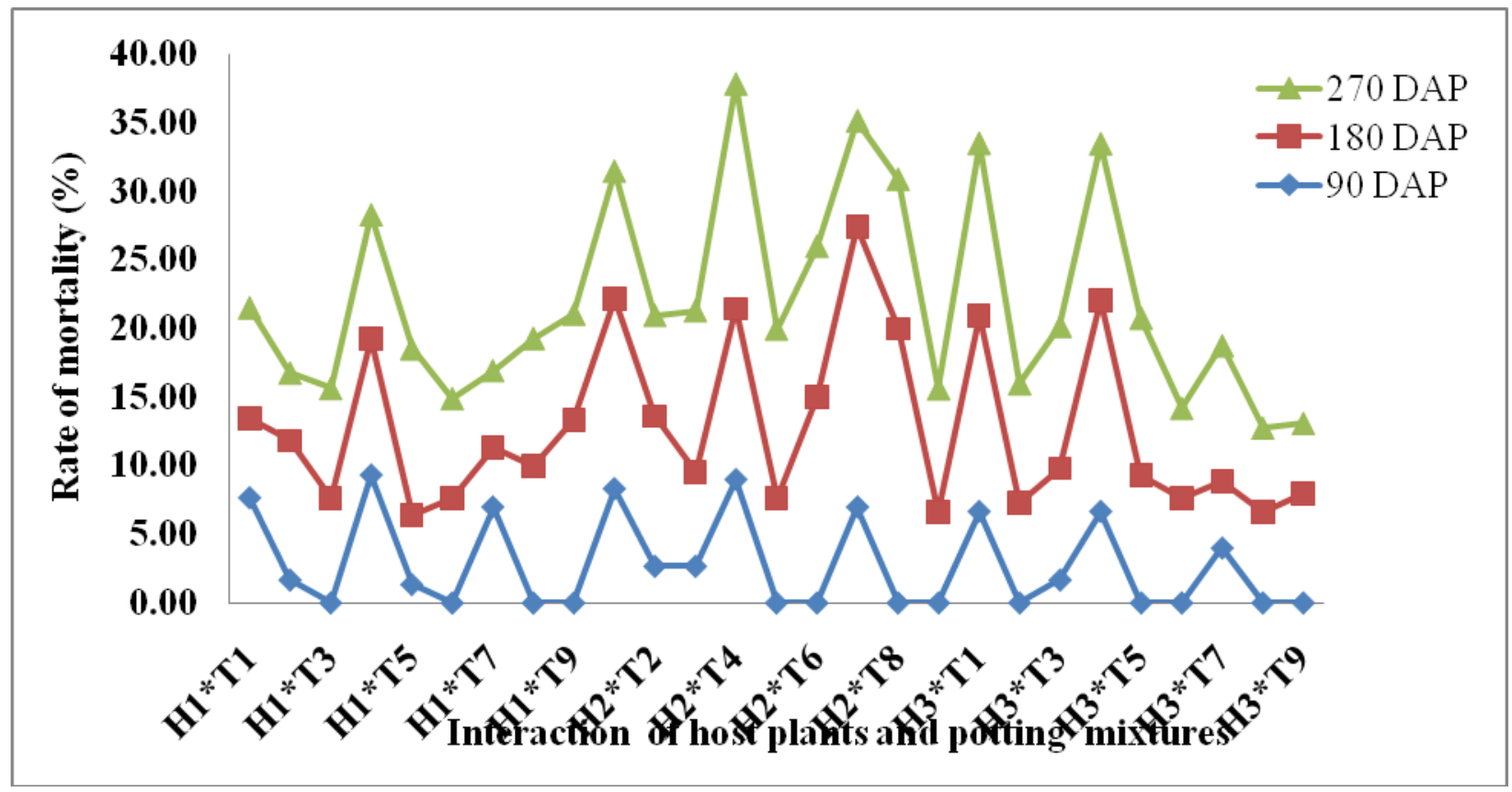

Fig.4 Effect of host and potting mixture on height of sandal seedlings at an interval of 90 days

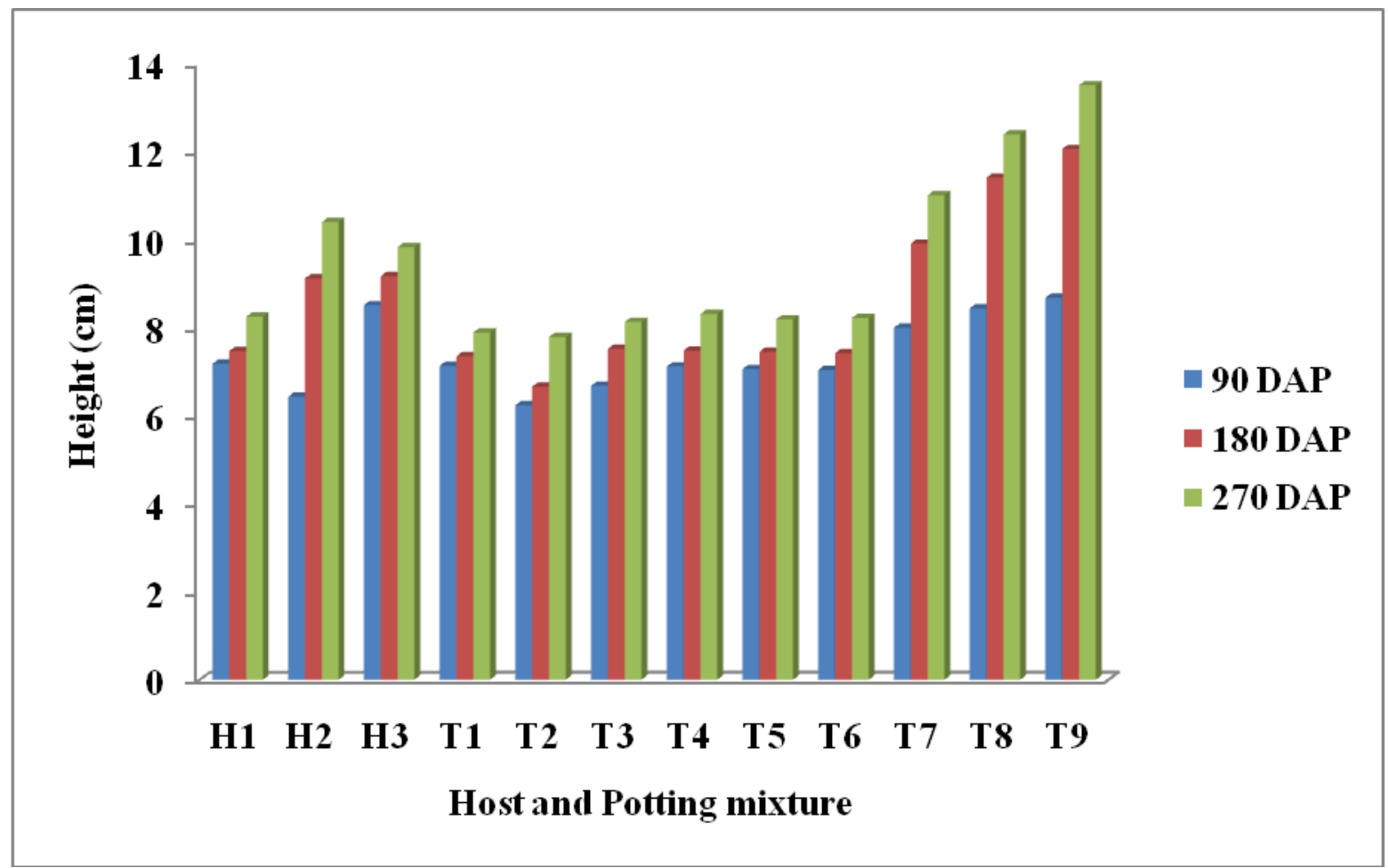


Fig.5 Interaction effect of host plants and treatment (potting mixture) on height of sandal seedlings at an interval of 90 days

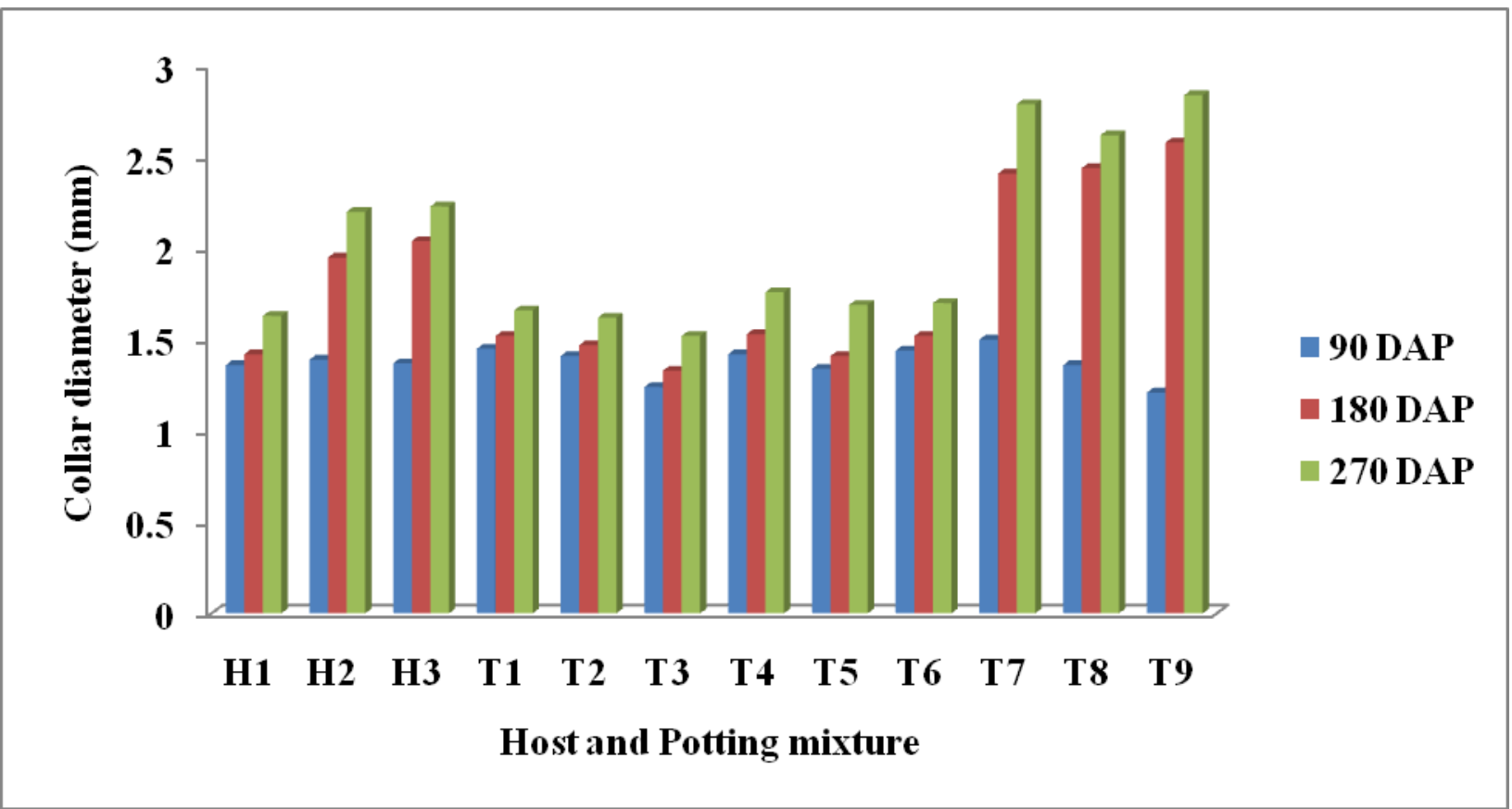

Fig.6 Influence of host and treatment (potting mixture) on collar diameter of sandal seedlings at an interval of 90 days

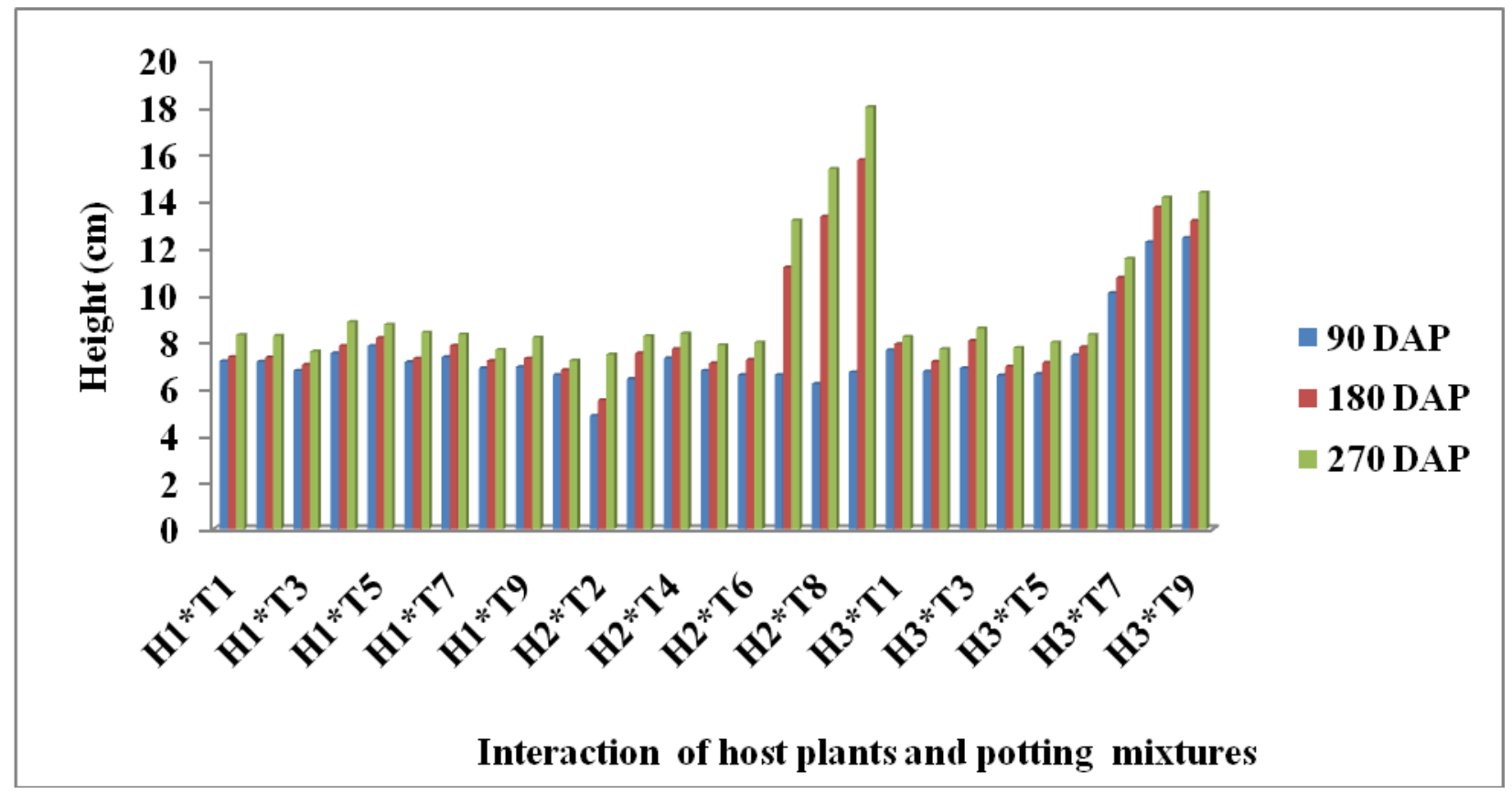


Fig.7 Interaction effect of host and treatment on collar diameter of sandal seedlings at an interval of 90 days

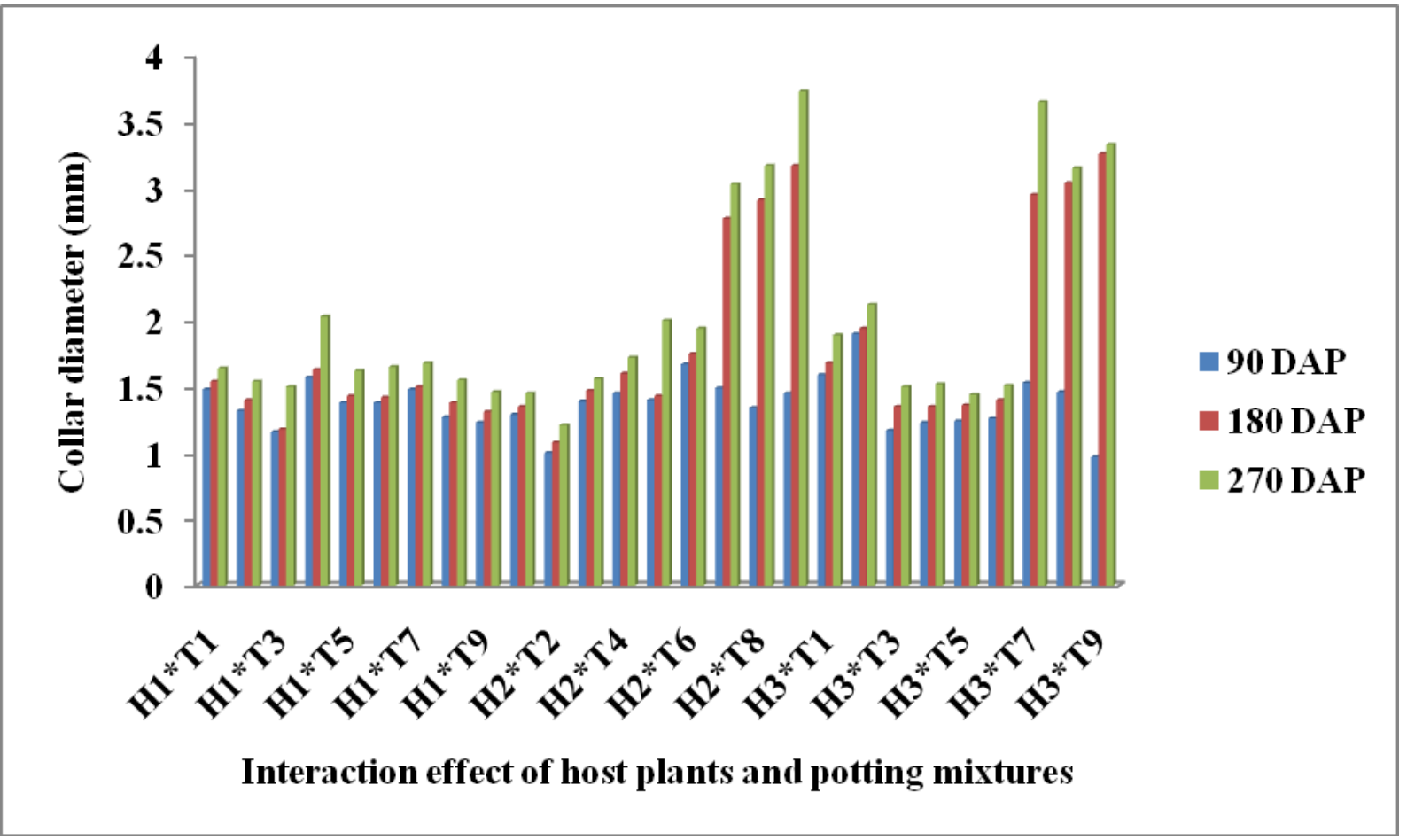

Fig.8 Relative growth rate for height, collar diameter and leaves of sandal seedlings after 270 days of transplanting

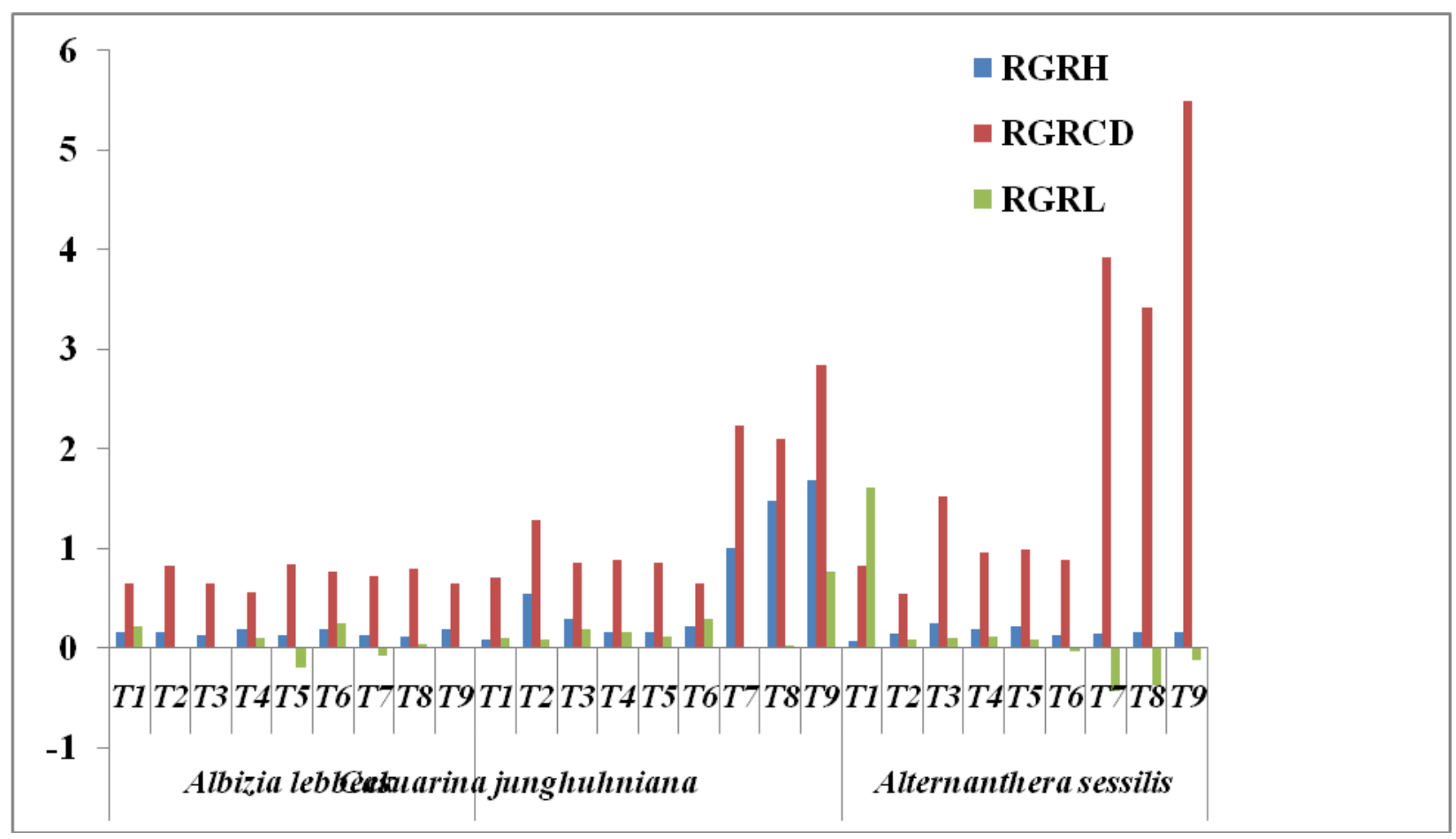


After 180 days of transplanting, there was significant difference in the collar diameter of seedlings and pot host $\mathrm{H} 3$ had effected higher collar diameter $(2.04 \mathrm{~mm})$ in sandal, followed by $\mathrm{H} 2(1.95 \mathrm{~mm})$. Similar increasing trend was recorded in $\mathrm{H} 3(2.33 \mathrm{~mm})$ followed by $\mathrm{H} 2$ $(2.20 \mathrm{~mm})$ after 270 days of transplanting (Table 3 and Fig 5. The probable nature of spreading branches and trimming off host A.sessilis might have increased the size of the sandal seedlings.

In the sub-plot treatment sand, soil, vermicompost and G.intraradices (T9) had higher collar diameter $(2.58 \mathrm{~mm})$ followed by sand, soil, vermicompost and G.fasiculatum (T8) which was $2.44 \mathrm{~mm}$. This can be attributed to activity of mycorrhizal fungi which might have resulted in absorption and mobility of organic nutrients in the potting mixture.

After 90 days of transplanting, interaction effect of $\mathrm{H} 3 * \mathrm{~T} 2$ had higher collar diameter $(1.90 \mathrm{~mm})$. After 180 of transplanting, interaction effect of $\mathrm{H} 3{ }^{*} \mathrm{~T} 9$ had higher collar diameter $(3.26 \mathrm{~mm})$. After 270 of transplanting, interaction of $\mathrm{H} 2 * \mathrm{~T} 9$ had higher collar diameter $(3.73 \mathrm{~mm})$ (Fig 6 and 7$)$. The interaction of the host and potting mixture also resulted in higher uptake of nitrogen, phosphorus and potassium as evident from the analysis. These results are in line with findings of Nagaveni et al., (1998)who opined that $S$. album seedlings inoculated with Glomus sp. performed better than uninoculated seedlings in terms of water relations and nutrient content.

\section{Relative growth rate}

\section{Relative growth rate for height (RGRH)}

The seedlings with primary host A. lebbeck (H1)along with potting mixtures burnt rice husk, soil and FYM (T4), burnt rice husk, soil, FYM and G.intraradices (T6) and sand, soil, vermicompost and G.intraradices (T9) had higher growth rate for height (0.18). In case of C. junghuhniana $(\mathrm{H} 2)$ was used as primary host, T9 recorded higher growth rate (1.69). In Alternanthera sessilis (H3), relative growth rate for height of the sandal seedlings along with potting mixture sand, soil, FYM and G.intraradices (T3) had higher height growth rate (0.24) (Table 4 and Fig 8).

\section{Relative growth rate for collar diameter (RGRCD)}

The sandal seedlings grown with A.lebbeck (H1) along burnt rice husk, soil, FYM and G.fasiculatum (T5) had considerable growth rate for collar diameter (0.84). The seedlings growth with $C$. junghuhniana $(\mathrm{H} 2)$ along with potting mixture sand, soil, vermicompost and G.intraradices(T9) had higher collar diameter growth rate (2.84).The seedlings grown with sand, soil, vermicompost and G.intraradices (T9) and A.sessilis(H3)as primary host had recorded higher collar diameter growth rate (5.49).

The combination of Casuarina junghuhiana as primary host and potting mixture consisting of sand, soil, vermicompost with G.intraradices, showed higher growth rate for height and collar diameter (1.69 and 2.84, respectively) and lesser growth rate in A.sessilis with sub treatment sand, soil and FYM (0.07 and 0.54 respectively). Guissou et al., (2016) reported positive effects of mycorrhizae on seedlings survival and growth under nursery conditions and even documented increased growth rate in terms of height and collar diameter. The growth rate also can be attributed to organic carbon created due to host plants, decay of dead pruning materials in the polythene bags, nodulation and nitrogen fixing by nonnitrogen fixing host plants. The growth rate also can be confined to activity of G.intraradices in uptake of nutrient especially phosphorus and potassium 


\section{Acknowledgement}

We acknowledge the college of Forestry, Ponnampet and Karnataka Forest department for providing all the facilities to carry out the research.

\section{References}

Ananthapadmanabha, H. S., 2000, Sandalwood and its marketing trend. My For., 36:147-152.

Annapurna, D., 2002, Investigations on seed variability, germination and modern nursery practices for mass production of quality seedlings of sandalwood, Santalum album L. Ph.D.thesis, FRI Deemed Univ., Dehra Dun, India.

Annapurna, D., Rathore, T. S. And Joshi, G., 2007, Integrated nursery practices for mass production of quality planting stock of Santalum album L. Proc. of National Seminar in IWST, Bangalore 12-13, December, 2007, pp 67-73.

Caravaca, F., Barea, J. M., Palenzuela, J., Figueroa, D., Alguacil, M. M. And Roldan, A., 2003, Establishment of shrub species in a degraded semiarid site after inoculation with native or allochthonous arbuscular mycorrhizal fungi. App. Soil Ecol., 22: 103-111.

Dutt, S. and Verma, K. S., 2005, Effect of collection of time, pre-sowing treatments and sowing time on the germinability of sandal (Santalum album L.) seeds under nursery conditions. J. Non-Timber For. Prod., 12(4):205-208.

Ehrhart, Y. and Fox, J. E. D., 1995, State of knowledge regarding cultivation of sandalwood.

Gairola, S., Aggarwal, P. S. and Ravikumar, G. S., 2008, Status of production and marketing of sandalwood (Santalum album L.). Proc. National Seminar on Conservation,

Improvement,
Cultivation and Management of Sandal. Institute of Wood Science and Technology, Bangalore., pp. 1-8.

Guissou, T., Babana, A. H., Sanon, K. B. and B A, A. M., 2016, Effects of arbuscular mycorrhizae on growth and mineral nutrition of greenhouse propagated fruit trees from diverse geographic provenances. Biol. Agron. Soc. Environ., 20(3): 417-426.

Iyengar, A. V., 1960, The relation of soil nutrients to the incidence of spike disease in Sandalwood (Santalum album Linn.). Indian For., 86(4):22030.

Lakshmisita L. G. And Bhattacharya A., 1998, Sandal and Its Products. Proc. of an Int. seminar, December, 1997, 18: pp. 19.

Liu, X. J., Xu, D. P., Xie, Z. S. and Zhang, N.N., 2009, Effects of different culture media on the growth of Indian sandalwood (Santalum album L.) seedlings in Zhanjiang, Guangdong, southern China. For. Studies in China, 11(2):pp.132-138.

Nagaveni, H. C., Vijayalakshmi, G., Annapurna, $\quad$ D. And Ananthapadmanabha, H. S., 1998, Association of sandal with vesicular arbuscular mycorrhiza (VAM) fungi. pp 135-146 in Radomiljac A M et al., (eds) Sandal and its Products AICAR, Proc. Series. December18-19, 1998, Malleswaram.

Radomiljac, A. M., 1994, The influence of pot host species, seedling age and nursery nutrition on Santalum album Linn. Plantation establishment. Ord River Irrigation Area, Western Australia. In papers presented at the Sandalwood workshop held at Noumea, New Caledonia, August 112, 1994. Australian Centre for International Agricultural Research (ACIAR). CIRAD/FAO. pp. 60-78. 
Radomiljac, A. M. And Mccomb, J. A., 1998, Nitrogen-fixing and non-nitrogenfixing woody host influences on the growth of the root hemi-parasite Santalum album $\mathrm{L}$.

Rai, S. N., 1990, Status and cultivation of sandalwood in India. Hamilton, Lawrence; Conrad, C. Eugene, technical coordinators. Proc. of the Symposium on Sandalwood in the Pacific; April 9-11, 1990; Honolulu, Hawaii. Gen. Tech. Rep. PSW-GTR122. Berkeley, CA: Pacific Southwest Research Station, Forest Service, US Department of Agriculture, 122:66-71

Rangaswamy, C. R., Ananthapadmanabha, H. S., Jain, S. H. and Nagaveni, H. C., 1986, Nutrient uptake and host requirement of sandal. Van vigyan, 24(3-4):75-79.

Srinivasan, V. V., Sivaramakrishnan, V. R., Rangaswamy, $\quad$ C. $\quad$ R.,
Ananthapadmanabha, H. S. And Shankaranarayana, M. H. 1992, In: Sandal (Santalum album L.). Published by the Director, Institute of Wood Science and Technology (ICFRE), Bangalore, India. pp. 232.

Surata, K., 1992, Effect of host plants on growth of sandalwood (Santalum album) seedlings. Santalum, 9:1-10.

Surendran, C., Parthiban, K. T., Bhuvaneswaran, C. and Murugesh, M., 1998, Silvicultural strategies for augmentation of sandal regeneration. In Aciar Proc. Australian Centre For International Agricultural Research. pp. 69-73

Viswanath, S., Dhanya, B. And Rathore, T. S., 2009, Domestication of Sandal (Santalum album L.) in India: constraints and prospects. APA News, (34):9-12.

\section{How to cite this article:}

Shubhashree Sahu, V. Maheswarappa, Ramakrishna Hegde, R. N. Kencharaddi and Sathish, B. N. 2021. Effect of Host Plants and Potting Mixture on Growth of Sandalwood Seedlings at Nursery Stage. Int.J.Curr.Microbiol.App.Sci. 10(09): 545-559. doi: https://doi.org/10.20546/ijcmas.2021.1009.063 